\title{
Comparison of Analytical and Numerical Models of Adsorber/desorber of Silica Gel-water Adsorption Heat Pump
}

\author{
Katarzyna Zwarycz-Makles"1, Wladyslaw Szaflik ${ }^{2}$ \\ ${ }^{1}$ Department of Heating, Ventilation and Heat Engineering, West Pomeranian University of Technology in \\ Szczecin, Piastow 50, 71-311 Szczecin, Poland \\ e-mail: kzwarycz@zut.edu.pl \\ ${ }^{2}$ Department of Heating, Ventilation and Heat Engineering, West Pomeranian University of Technology in \\ Szczecin, Piastow 50, 71-311 Szczecin, Poland \\ e-mail: wladyslaw.szaflik@ zut.edu.pl
}

Cite as: Zwarycz-Makles, K., Szaflik, W., Comparison of Analytical and Numerical Models of Adsorber/desorber of Silica Gel-water Adsorption Heat Pump, J. sustain. dev. energy water environ. syst., 5(1), pp 69-88, 2017 , DOI: http://dx.doi.org/10.13044/j.sdewes.d5.0134

\begin{abstract}
In the paper, comparison of an analytical and a numerical model of silica gel/water adsorber/desorber is presented. Adsorber/desorber as a part of the two-bed single-stage adsorption heat pump is discussed. The adsorption heat pump under consideration consists of an evaporator, two adsorber/desorber columns and a condenser. Only heat and mass transfer was taken into account during operation of assumed adsorption heat pump. Adsorption equilibrium was described by the Dubinin-Astachov model. The presented mathematical models, both analytical and numerical, were created to describe the temperature, heat and concentration changes in the adsorber/desorber and consequently to describe the performance of the adsorption heat pump. Heat and mass transfer equations of the model were solved analytically and calculation parameters were entered in the common spreadsheet. The numerical model was established comprising of the set of heat and mass balance partial differential equations, together with the initial and boundary conditions and was solved by the numerical method of lines. The developed analytical model is very basic and can be used only for the initial estimates of mean cyclic temperature of the cooling/heating water in the adsorber/desorber bed. Validation of the numerical model shows reasonable agreement between the numerical and experimental averaged bed temperatures and is an indication of the proper mathematical modeling and the accuracy of the numerical analysis.
\end{abstract}

\section{KEYWORDS}

Adsorption heat pump, Silica gel adsorbent, Adsorption modeling.

\section{INTRODUCTION}

With the aim to reduce the amount of primary energy used for domestic heating purposes, the introduction of heat driven heat pumps can provide a significant improvement in fossil fuel utilisation [1]. Recently a large amount of research has been done on various types of adsorption heat pumps, as an alternative to vapor compression systems. Performance of adsorption systems for heating and air conditioning was discussed by Restuccia and Cacciola [2], performance with taking into account

\footnotetext{
* Corresponding author
} 
regeneration in [3, 4], as well as performance for a four-bed adsorption heat pumpin [5]. Basic principles, theories and cycle performance thermodynamics of solid adsorption solar refrigeration was presented in [6], even new type of adsorber for an adsorption ice maker on fishing boats was designed [7]. An interesting theoretical study [8] was performed to investigate the potential of storing thermal energy using a heat pump which is a thermo-chemical storage system consisting of water as sorbate, and sodium chloride as the sorbent.

Adsorption processes are widely used in the chemical industry, environmental protection and other fields, i.e., for adsorption with chemical reactions [9, 10], for separation and purification of gases and liquids [11], in the thermal swing adsorption systems [12].

During the past two decades, this phenomenon has been exploited to produce cooling and heating [13]. In [14, 15] the possibilities and limits of this technology are analysed. Solid-gas sorption heat powered cycles appear to be an attractive alternative for cooling [16] or air conditioning applications [17]. Cogeneration of fuel cell and sorption air conditioning systems was widely analysed in [18].

Adsorption heat pumps have, aside from environmental benefits, several advantages compared to conventional vapor compression systems, such as: simplicity, no moving parts, low maintenance requirements, and the use of stable, non-toxic reactants, as adsorbents and adsorbates [1]. They also have disadvantages: the discontinuity of action, high-design requirements for maintaining a vacuum, large size and relatively low Coefficient Of Performance (COP) [19].

The operation of adsorption heat pumps is based on the ability of the porous adsorbent to adsorb vapor (adsorbate) at low temperature, and to desorb it when heated. The performance of an adsorption heat pump is controlled by many parameters, such as adsorbent and adsorbate properties, system design and operating conditions.

There are several adsorbent-adsorbate working pairs for solid adsorption system [20]. The major adsorbates used are water, ammonia, and methanol. Conventional adsorbents are: zeolite molecular sieves [21], silica gel [22], alumina and active carbon [23]. Most new adsorbents are based on modification of existing one [21], to increase the adsorption capacity and to improve the heat and mass transfer.

\section{SILICA GEL-WATER ADSORPTION HEAT PUMP}

In the paper, comparison of an analytical and a numerical model of silica gel/water adsorber/desorber is presented. Adsorber/desorber as a part of the two-bed single-stage adsorption heat pump is discussed (dashed line rectangles in Figure 1).

Silica gel-water pair was used because it is considered suitable for utilizing low temperature heat sources i.e., waste heat, geothermal water as driving heat source for the heat pump. Only heat transfer and mass transfer were taken into account during operation of the assumed adsorption heat pump. The adsorption heat pump under consideration consists of an evaporator, two adsorber/desorber columns and a condenser. In the adsorption heat pump there are two basic circuits:

- Closed internal circuit - the adsorbate (water vapor as refrigerant) circulates from the evaporator thru adsorber/desorber to the condenser, where refrigerant vapor turns into liquid (as it is cooled down by cooling water). The condenser is connected to the evaporator with a pipe to flow liquid refrigerant to the evaporator;

- Open external circulation - as the heat/cold transport outside the device with the heating/cooling water.

The operation of the heat pump includes a number of cyclic transient processes. These processes run at different temperature and pressure levels. The adsorption process is followed by a preheating process to raise the temperature and to lift up the pressure of the 
sorption reactor up to the condenser pressure. Desorption process starts afterward, then the temperature of sorption reactor approaches the heat source temperature over time. Next, the precooling process starts; it cools down the adsorber/desorber to lower the pressure to the evaporator pressure. When the refrigerant from the evaporator is transported to the condenser and returns to the evaporator then one cycle is completed and restarts circulation again [24].

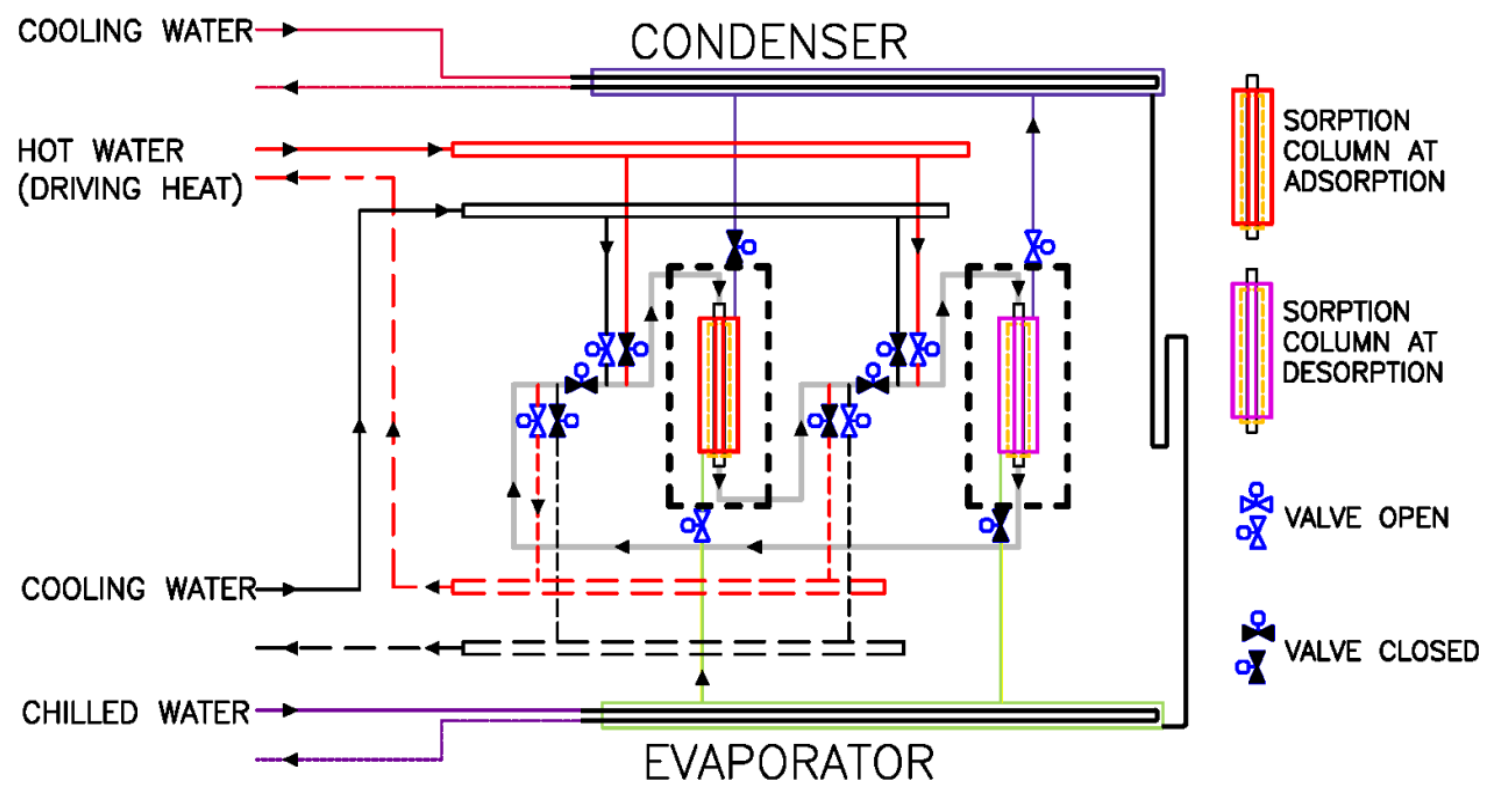

Figure 1. Configuration of the two-bed single-stage adsorption heat pump, modelled adsorber/desorber (dashed line rectangles) under consideration

Example of Clapeyron diagram for one cycle of discussed two-bed single-stage adsorption heat pump is presented in Figure 2 (diagram based on analytical model). The kink at the beginning of isobaric adsorption/desorption in Figure 2 is caused by the assumed mechanism of process pressure changes during the cycle.

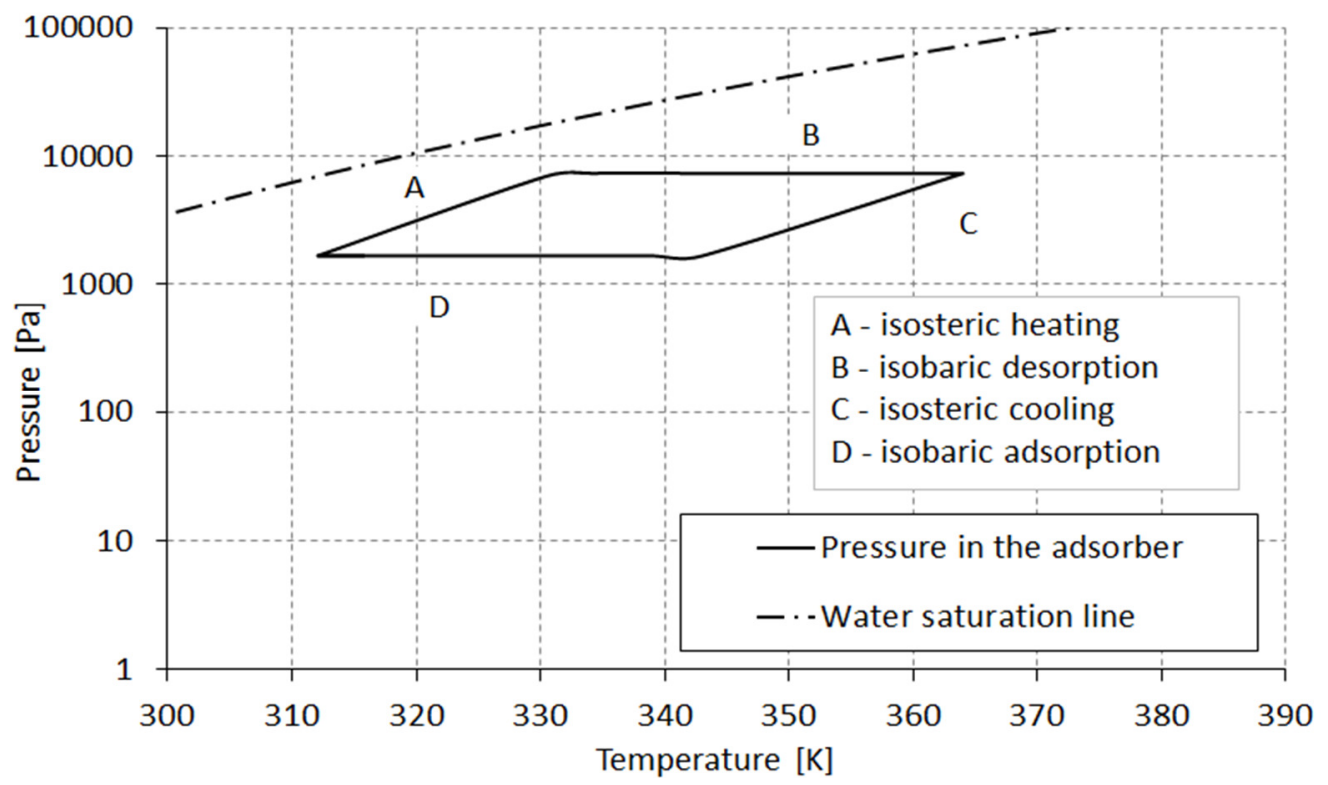

Figure 2. Calculated pressure $p$ in the adsorber based on presented analytical model (Clapeyron diagram for one cycle); $T_{\text {cond }}=313 \mathrm{~K}, T_{\text {evap }}=288 \mathrm{~K}, T_{\text {des }}=363 \mathrm{~K}, T_{\text {ads }}=313 \mathrm{~K}$, $\tau_{\text {cycle }}=360 \mathrm{~s}$, pressure - adsorption $=1.7 \mathrm{kPa}$, desorption $=7.3 \mathrm{kPa}$ 


\section{MODELING OF THE SORPTION COLUMN}

The presented mathematical models, both analytical and numerical, were created to describe the temperature, heat and concentration changes in the adsorber/desorber and consequently to describe the performance of the adsorption heat pump [25-27]. Part of the assumptions for both considered models is shared and listed below:

- Pressure losses of vapor as the adsorbate flows from the evaporator to silica gel grains and from grains to the condenser were negligibly small;

- During the adsorption process, pressure inside the adsorber/desorber was equal to that inside the evaporator;

- During the desorption process, pressure inside the adsorber/desorber was equal to that inside the condenser;

- Average temperature of the reactor's cooling and hot water was constant;

- Average specific heat of the adsorbent was constant;

- Average specific heat of the water was constant;

- Thermal conductivity of the adsorbent was constant;

- The temperature inside the evaporator as well the condenser was constant;

- Vapor temperature and pressure during adsorption process was equal to the evaporator temperature and pressure;

- Vapor temperature during desorption process was related to the heat balance of the bed, and the vapor pressure during the desorption process was equal to condenser pressure;

- Switching between adsorption and desorption cycle (cooling water is switched to hot water) took place instantaneously.

For the temperature range encountered in both the evaporator and condenser, saturated water vapor pressure was determined by the Antoine equation [28], and with parameters from literature [29] was calculated as:

$$
\ln \left(p_{\mathrm{s}}\right)=18.3036-\frac{3816.44}{T-46.13}
$$

Adsorption equilibrium was described by the Dubinin-Astakhov model (D-A) [30] (parameters listed in Table 1):

$$
a_{\mathrm{eq}}=a_{0} \exp \left[-\left(\frac{A}{\beta E_{0}}\right)^{n}\right]
$$

where $A=R T \ln \left(p_{\mathrm{s}} / p\right)$ is an adsorption potential. Adsorption and desorption process dynamics was described by the application of the Linear Driving Force (LDF) model [31]. The equation to calculate the time dependent change in concentration for the working bed (silica gel) was described:

$$
\frac{\partial a}{\partial \tau}=k_{\mathrm{m}}\left(a_{\mathrm{eq}}-a\right)
$$

where $k_{\mathrm{m}}=15 D_{\mathrm{e}} / r_{\mathrm{a}}{ }^{2}$ is the mass transport equation and $D_{\mathrm{e}}=D_{0} \exp \left(-E_{\mathrm{a}} / R T\right)$. The heat of adsorption for both adsorption and desorption processes was determined by the Clausius-Clapeyron equation [30]:

$$
\Delta H_{\mathrm{a}}=R T^{2}\left(\frac{\partial \ln p}{\partial T}\right)_{a_{\mathrm{eq}}}
$$


Table 1. Parameter values for the Dubinin-Astakhov equation and other parameters used in the calculation

\begin{tabular}{cccc}
\hline Description & Symbol & Unit & Value \\
\hline Limiting adsorption amount & $a_{0}$ & {$\left[\mathrm{~kg} \mathrm{~kg}^{-1}\right]$} & 0.35 \\
Characteristic energy of the adsorbent & $\beta E_{0}$ & {$\left[\mathrm{~J} \mathrm{~mol}^{-1}\right]$} & $3,780.8$ \\
Constant in the Dubinin-Astakhov equation & $n$ & {$[-]$} & 1.016 \\
Process constant & $D_{0}$ & {$\left[\mathrm{~m}^{2} \mathrm{~s}^{-1}\right]$} & 0.000254 \\
Activation energy & $E_{\mathrm{a}}$ & {$\left[\mathrm{J} \mathrm{mol}^{-1}\right]$} & 42,000 \\
Particle radius & $r_{\mathrm{a}}$ & {$[\mathrm{mm}]$} & 0.1 \\
Bulk density of the bed particles & $\rho_{\mathrm{a}}$ & {$\left[\mathrm{kg} \mathrm{m}^{-3}\right]$} & 600 \\
Bulk density of the tube material & $\rho_{\mathrm{t}}$ & {$\left[\mathrm{kg} \mathrm{m}^{-3}\right]$} & 8,936 \\
Average specific heat of the bed & $c_{\mathrm{pa}}$ & {$\left[\mathrm{J} \mathrm{kg}^{-1} \mathrm{~K}^{-1}\right]$} & 924 \\
Average specific heat of the tube & $c_{\mathrm{pt}}$ & {$\left[\mathrm{J} \mathrm{kg}^{-1} \mathrm{~K}^{-1}\right]$} & 383 \\
Average specific heat of the water & $c_{\mathrm{pv}}$ & {$\left[\mathrm{J} \mathrm{kg} \mathrm{Kg}^{-1}\right]$} & 4,182 \\
Thermal conductivity of the bed & $\lambda_{\mathrm{a}}$ & {$\left[\mathrm{W} \mathrm{m} \mathrm{K}^{-1} \mathrm{~K}^{-1}\right]$} & 0.175 \\
Thermal conductivity of the tube & $\lambda_{\mathrm{t}}$ & {$\left[\mathrm{W} \mathrm{m} \mathrm{K}^{-1} \mathrm{~K}^{-1}\right]$} & 401 \\
Length of the tube & $L_{\mathrm{t}}$ & {$\left[\mathrm{m}^{-1}\right.$} & 1.5 \\
Linear heat transfer coefficient & $k_{\mathrm{l}}$ & {$\left[\mathrm{W} \mathrm{m} \mathrm{K}^{-1}\right]$} & 615 \\
Mass of the adsorbent $($ silica gel $)$ & $m_{\mathrm{a}}$ & {$[\mathrm{kg}]$} & 1.57 \\
Duration of the cycle $\left(\tau_{\mathrm{ads}}+\tau_{\mathrm{des}}\right)$ & $\tau_{\mathrm{cycle}}$ & {$[\mathrm{s}]$} & $180+180$ \\
Radius $R 1$ & $R 1$ & {$[\mathrm{~mm}]$} & 10 \\
Radius $R 2$ & $R 2$ & {$[\mathrm{~mm}]$} & 11 \\
Radius $R 3$ & $R 3$ & {$[\mathrm{~mm}]$} & 26 \\
Wall thickness of the tube & $\delta_{\mathrm{t}}$ & {$[\mathrm{mm}]$} & 1 \\
Deposited bed thickness & $\delta_{\mathrm{a}}$ & {$[\mathrm{mm}]$} & 15 \\
\hline
\end{tabular}

The adsorption equilibria of selected adsorbent-adsorbate pair were sourced from available literature [21, 23]. Validation of data obtained from D-A equation (used in calculation) based on published experimental data by Wang and LeVan in 2009 [22] was performed as well (Figure 3).

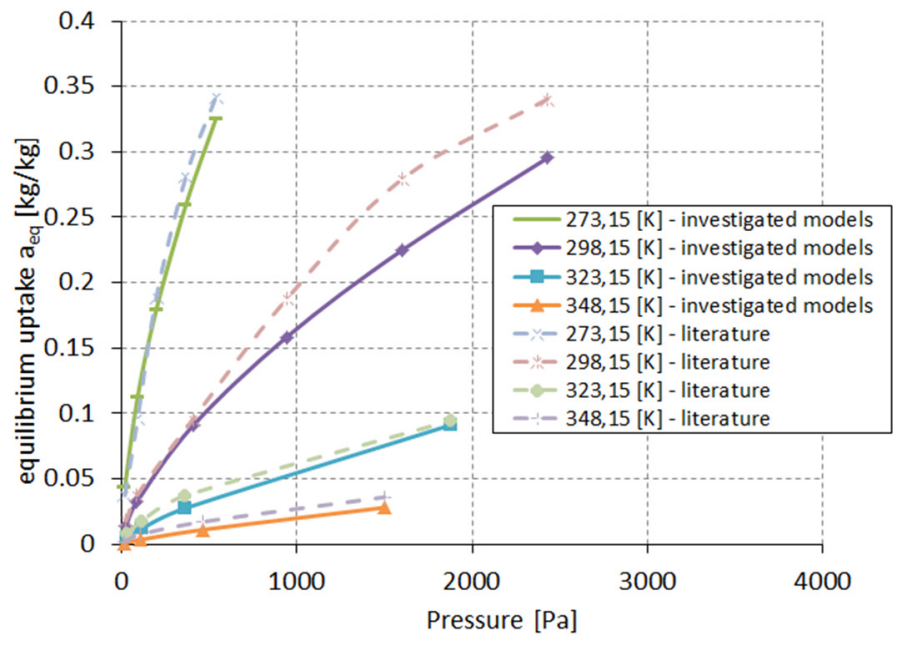

Figure 3. Adsorption equilibria of water on silica gel - validation of data obtained from D-A equation used in calculation and comparison with published experimental data [22]

Other assumptions, specific for models considered in the paper, were described in detail below, in the sections dedicated to each model. 


\section{Analytical model of the adsorber/desorber}

The presented one-dimensional analytical model was created to describe the temperature, heat and concentration changes in the adsorber/desorber and consequently to describe the performance of the adsorption heat pump. For analytically solved equations parameters were entered in the common spreadsheet. In the analytical model, it was assumed that for averaged parameters of the adsorbent and adsorbate, the lumped parameters model is applicable, considering the tubular geometry and aspect ratio.

Two packed bed sorption columns consist of tubes with deposited silica gel adsorbent (Figure 4 and Figure 5). The sorption column performs dual function: it works as an adsorber when cooled by cooling water and as a desorber when heated by hot water from outside. The adsorber/desorber is connected to the evaporator on one side while joined to the condenser on the other side with control valves. During the adsorption process, the adsorbate (refrigerant vapor) enters the adsorber after leaving the evaporator. When cooling water is switched to hot water, the adsorbate is directed to the condenser - this is the desorption phase. The design of the adsorber/desorber element arrangement is presented in Figure 4. The main calculation element (tube with deposited silica gel bed) contains three components that describe the adsorber/desorber heat and mass exchanger: heating/cooling water, metal pipe (tube of column), working bed (silica gel).

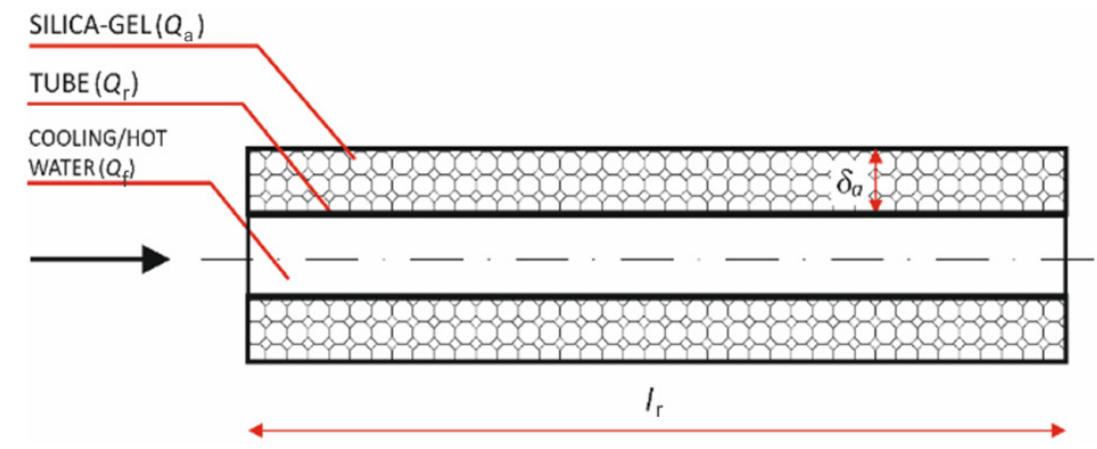

Figure 4. Design of the adsorber/desorber element (tube with deposited silica gel bed) - analytical model
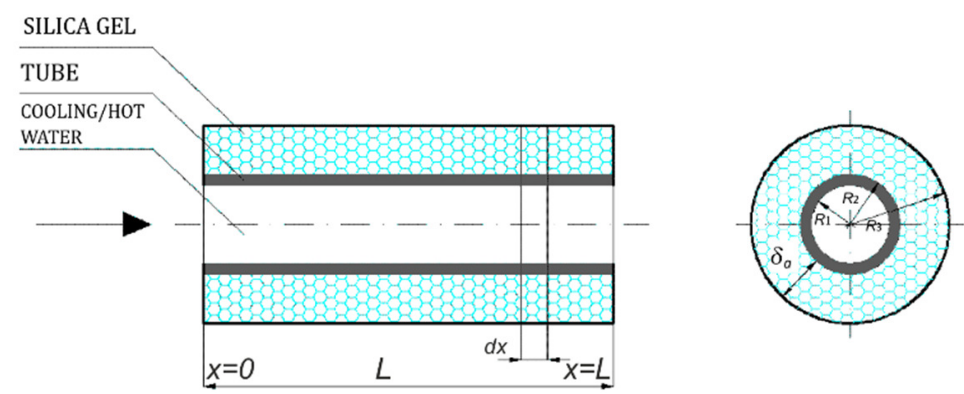

Figure 5. Design of the adsorber/desorber element (tube with deposited silica gel bed) - numerical model [25, 27, 32]

The adsorbed or desorbed heat can change the tube wall temperature, the adsorbent temperature as well as temperature of the adsorbed adsorbate. That heat can be then extracted by the cooling medium or delivered by the heating medium. The total heat storage capacity of the tube and of the adsorbent is taken into account, and further half of the heat storage capacity of the adsorbed adsorbate (averaged value over the $\Delta \tau_{\mathrm{i}}$ time interval). The assumption of the adsorption and desorption temperatures being constant within the $\Delta \tau$ time interval allows for constant values of $k_{\mathrm{m}}$ coefficients for both processes, respectively. The differential in eq. (3) can thus be solved and the mass of the 
adsorbate adsorbed by the adsorbent can be determined for the respective time interval. The adsorbent temperature is determined from the heat balance equation for the time interval:

$$
Q_{\mathrm{a}, \mathrm{i}}=Q_{\mathrm{r}, \mathrm{i}}+Q_{\mathrm{f}, \mathrm{i}}
$$

During the adsorption or desorption processes, the quantity of heat $Q_{\mathrm{a}, \mathrm{i}}$, transferred by the adsorbent deposited on a single tube, during the steady cyclic adsorption or desorption process, for a time interval, was determined from:

$$
Q_{\mathrm{a}, \mathrm{i}}=\Delta a \rho_{\mathrm{a}} l_{\mathrm{r}} \frac{\pi}{4}\left(d_{\mathrm{a}, \mathrm{ex}}^{2}-d_{\mathrm{a}, \mathrm{in}}^{2}\right) \frac{\Delta H_{\mathrm{a}}}{m_{\mathrm{m}}}
$$

where $\Delta a$ is change in the adsorbate mass adsorbed on the adsorbent in the time interval $\Delta \tau_{\mathrm{i}}$, from the starting instant until completion of the adsorption or desorption process.

The adsorbed or desorbed heat can change the tube wall temperature, the adsorbent temperature as well as temperature of the adsorbate. That heat can be then extracted by the cooling medium or delivered by the heating medium. The heat $Q_{\mathrm{r}, \mathrm{i}}$, transferred from adsorbent (silica gel) and adsorbate (water vapor) through the tube to the fluid (cooling/hot water) during the adsorption and desorption processes was determined from equation:

$$
Q_{\mathrm{r}, \mathrm{i}}=W_{\mathrm{i}}\left(T_{\mathrm{b}, \mathrm{i}}^{\prime \prime}-T_{\mathrm{b}, \mathrm{i}}^{\prime}\right)
$$

where $W_{\mathrm{i}}=W_{\mathrm{r}}+W_{\mathrm{a}}+W_{\mathrm{w}, \mathrm{i}}$ is the total heat storage capacity of the tube and of the adsorbent taken into account, as well further half of the heat storage capacity of the adsorbed adsorbate (averaged value over the $\Delta \tau$ time interval). Heat $Q_{\mathrm{f}, \mathrm{i}}$ transferred to the fluid (cooling/hot water) was determined for the time averaged temperature of the desorption or adsorption process. Heat transfer is assumed to take place between the middle line of the adsorbent layer and the heating or cooling medium, respectively. It is further assumed that the average temperature of adsorbent and tube's wall $T_{\mathrm{b}, \mathrm{i}}$ is equal to the arithmetic mean of the temperature values $T_{\mathrm{b}, \mathrm{i}}^{\prime}$ and $T_{\mathrm{b}, \mathrm{i}}^{\prime \prime}$ at the beginning and end of the time interval respectively:

$$
Q_{\mathrm{f}, \mathrm{i}}=\pi l_{\mathrm{r}}\left(\frac{T_{\mathrm{b}, \mathrm{i}}^{\prime}+T_{\mathrm{b}, \mathrm{i}}^{\prime \prime}}{2}-T_{\mathrm{f}, \mathrm{i}}\right) k_{\mathrm{l}} \Delta \tau_{\mathrm{i}}
$$

where $k_{1}$ is the linear heat transfer coefficient. Some further transformations (described in [24-26]) lead to the following relationship of the tube and adsorbent temperature at the end of the time interval $\Delta \tau_{\mathrm{i}}$. Additional assumption was made that the temperature of adsorbent $T_{\mathrm{a}, \mathrm{i}}^{\prime \prime}$ is approximately equal to the temperature of the adsorbent and tube's wall $T_{\mathrm{b}, \mathrm{i}}$ due to negligibly small differences:

$$
T_{\mathrm{a}, \mathrm{i}}^{\prime \prime} \cong T_{\mathrm{b}, \mathrm{i}}^{\prime \prime}=\frac{Q_{\mathrm{a}, \mathrm{i}}+W_{\mathrm{i}} T_{\mathrm{b}, \mathrm{i}}^{\prime}-\pi l_{\mathrm{r}}\left(\frac{T_{\mathrm{b}, \mathrm{i}}^{\prime}}{2}-T_{\mathrm{f}, \mathrm{i}}\right) k_{\mathrm{l}} \Delta \tau_{\mathrm{i}}}{2+\frac{\pi l_{\mathrm{r}} k_{\mathrm{l}} \Delta \tau_{\mathrm{i}}}{W_{\mathrm{i}}}}
$$

In the model the effect of temperature of supply and return heating/cooling water on heat exchange and adsorption/desorption in the adsorption heat pump was taken into 
account. In the expanded model the cooling down of the heating medium (temperature drop) or the heating up of the cooling medium (temperature rise) in the bed in an assumed time step $\Delta \tau_{\mathrm{i}}$ is calculated by dividing the heat supplied to/released from) adsorbent in the previous time step $\Delta \tau_{\mathrm{i}-1}$ by the heat capacity of the thermal capacity factor:

$$
\Delta T_{\mathrm{f}, \mathrm{i}}=\frac{Q_{\mathrm{f},(\mathrm{i}-1)}}{W_{\mathrm{f}}}
$$

The final temperature of the fluid is determined by subtracting the temperature drop or temperature rise of the fluid to the initial temperature in the assumed step (the final temperature of the previous step):

$$
T_{\mathrm{f}, \mathrm{i}}^{\prime \prime}=T_{\mathrm{f}, \mathrm{i}-1}^{\prime \prime} \mp \Delta T_{\mathrm{f}, \mathrm{i}}
$$

The average temperature of the heating/cooling medium $T_{\mathrm{f}, \mathrm{i}}$ is equal to the arithmetic mean of the initial temperature $T_{\mathrm{f}, \mathrm{i}}^{\prime}$ and final temperature at the time interval $T_{\mathrm{f}, \mathrm{i}}^{\prime \prime}$ :

$$
T_{\mathrm{f}, \mathrm{i}}=\frac{T_{\mathrm{f}, \mathrm{i}-1}^{\prime}+T_{\mathrm{f}, \mathrm{i}}^{\prime \prime}}{2}
$$

After taking into account time intervals $\Delta \tau_{\mathrm{i}}$, the heat accumulated in the condenser can be determined on the basis of the adsorbate (water vapor) mass desorbed by the adsorbent:

$$
Q_{\text {cond }}=H_{\text {des }} \Delta m_{\mathrm{v}, \mathrm{des}}
$$

where $Q_{\text {cond }}$ is heat of condensation at the condenser temperature, and $\Delta m_{\mathrm{v}, \text { des }}$ is mass of water vapor (adsorbate) condensed at condenser equals to mass of water vapor desorbed on adsorbent during desorption period. The heat quantity extracted in the evaporator $Q_{\text {evap }}$ :

$$
Q_{\text {evap }}=H_{\mathrm{ev}} \Delta m_{\mathrm{v}, \mathrm{ads}}
$$

where $H_{\mathrm{ev}}$ is vaporization heat at the evaporator temperature, and $\Delta m_{\mathrm{v} \text {,ads }}$ is mass of water vapor (adsorbate) evaporated at evaporator equals to mass of water vapor adsorbed on adsorbent during adsorption period. The heat taken by the cooling water during adsorption can be calculated from the following relationship:

$$
Q_{\mathrm{ads}}=\sum_{i=1}^{i=n}\left[\Delta H_{\mathrm{a}, \mathrm{i}} \Delta m_{\mathrm{v}, \mathrm{ads}, \mathrm{i}}+W_{\mathrm{i}}\left(T_{\mathrm{a}, \mathrm{i}}^{\prime \prime}-T_{\mathrm{a}, \mathrm{i}}^{\prime}\right)\right]
$$

where $\Delta m_{\mathrm{v}, \text { ads,i }}$ (mole) is the amount of water vapor (adsorbate) desorbed during desorption within the time interval $\Delta \tau_{\mathrm{i}}$. The heat supplied by the hot water during the adsorbent regeneration (desorption) affects the desorption of the adsorbate and increases the temperature of the tube with the deposited adsorbent. Its value can be calculated from the following relationship:

$$
Q_{\mathrm{des}}=\sum_{i=1}^{i=n}\left[\Delta H_{\mathrm{a}, \mathrm{i}} \Delta m_{\mathrm{v}, \mathrm{des}, \mathrm{i}}+W_{\mathrm{i}}\left(T_{\mathrm{a}, \mathrm{i}}^{\prime \prime}-T_{\mathrm{a}, \mathrm{i}}^{\prime}\right)\right]
$$


where $\Delta m_{\mathrm{v}, \mathrm{des}, \mathrm{i}}$ [mole] is the amount of water vapor (adsorbate) desorbed during desorption within the time interval $\Delta \tau_{\mathrm{i}}$.

The mathematical model was solved analytically. To analytically solve the equations, parameters were entered in the common spreadsheet. The elementary time interval was equal to $\Delta \tau_{\mathrm{i}}=1 \mathrm{~s}$.

\section{Numerical model of the adsorber/desorber}

A one-dimensional numerical model was created to describe the temperature and concentration changes in the adsorbers/desorbers and to compare the results of described heat pump performance with results from analytical model. Based on the model described in $[25,27,32]$ the mathematical model was established comprising the set of heat and mass balance Partial Differential Equations (PDE), together with the initial and boundary conditions and is solved by the Numerical Method Of Lines (NMOL). The PDE are reduced to a set of Ordinary Differential Equations (ODE) and is solved in POLYMATH 6.0 programming environment. The simulation software algorithm allowed calculation of various simulation scenarios automatically.

The main calculation element (adsorption/desorption column) contains components that describe the adsorber/desorber heat and mass exchanger: heating/cooling water, metal pipe (tube of column), working bed (silica gel) as presented in Figure 5. For each calculation sub-element (Figure 6) the heat and mass balance PDE were formulated (described in detail in [25, 27, 32]).

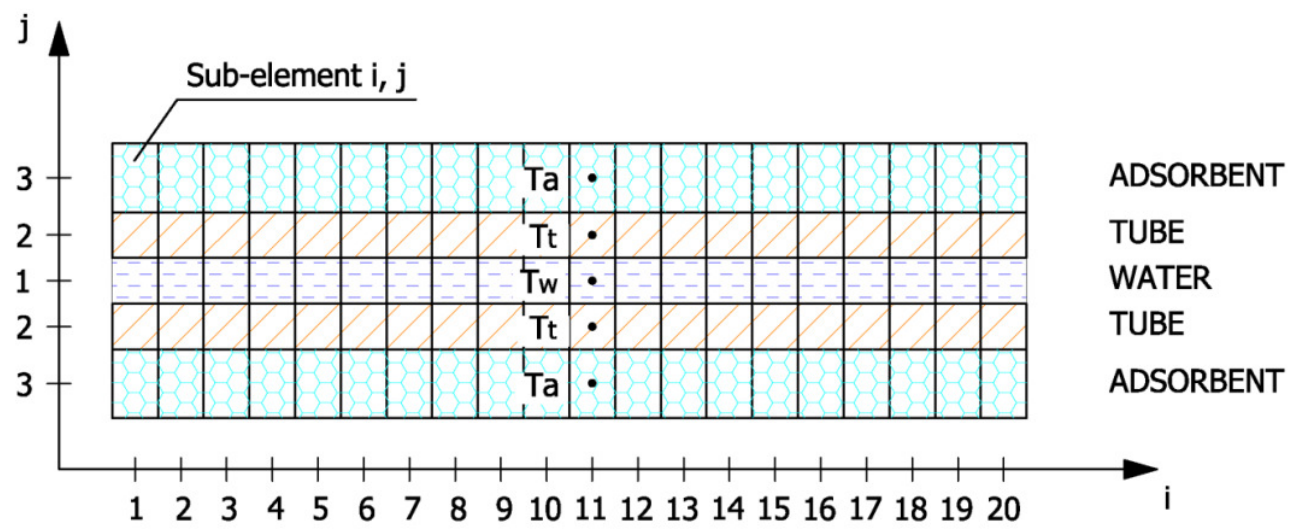

Figure 6. Design of the calculation sub-elements of adsorber/desorber with deposited silica gel bed $[25,27,32]$

The heat and mass balance equations in the calculation sub-element take into account the heat flow supplied to the process $\dot{Q}_{\mathrm{s}}$, the heat flow generated $\dot{Q}_{\mathrm{g}}$, the heat flow discharged from the process $\dot{Q}_{\mathrm{r}}$, and the heat flow accumulated in the process $\dot{Q}_{\mathrm{ac}}$. The following energy balance was written for all sub-elements of the model:

$$
\dot{Q}_{\mathrm{ac}}=\dot{Q}_{\mathrm{s}}-\dot{Q}_{\mathrm{r}}+\dot{Q}_{\mathrm{g}}
$$

The energy balance equations for water sub-element:

$$
\begin{gathered}
\dot{Q}_{\mathrm{s}}=\dot{Q}_{\mathrm{L}}+\dot{m} \cdot c_{\mathrm{pf}} \cdot T_{\mathrm{fLE}} \\
\dot{Q}_{\mathrm{r}}=\dot{Q}_{\mathrm{RI}}+\dot{m} \cdot c_{\mathrm{pf}} \cdot T_{\mathrm{fRI}}+\dot{Q}_{\mathrm{t}} \\
\dot{Q}_{\mathrm{g}}=0
\end{gathered}
$$


The energy balance equations for metal tube sub-element:

$$
\begin{gathered}
\dot{Q}_{\mathrm{s}}=\dot{Q}_{\mathrm{LE}}+\dot{Q}_{\mathrm{t}} \\
\dot{Q}_{\mathrm{r}}=\dot{Q}_{\mathrm{RI}}+\dot{Q}_{\mathrm{a}} \\
\dot{Q}_{\mathrm{g}}=0
\end{gathered}
$$

The energy balance equations for working bed (silica gel) sub-element:

$$
\begin{gathered}
\dot{Q}_{\mathrm{s}}=\dot{Q}_{\mathrm{LE}}+\dot{Q}_{\mathrm{a}} \\
\dot{Q}_{\mathrm{r}}=\dot{Q}_{\mathrm{RI}} \\
\dot{Q}_{\mathrm{g}}=\dot{Q}_{\mathrm{ads}, \mathrm{des}}
\end{gathered}
$$

In order to solve the set of above equations the full mathematical model requires following boundary conditions formulated for described calculation elements. For the first cycle at the time $t=0$ the temperatures of sub-elements of column are equal to $T_{0}$ :

$$
\left(T_{\mathrm{f}}\right)_{t=0}=\left(T_{\mathrm{t}}\right)_{t=0}=\left(T_{\mathrm{a}}\right)_{t=0}=T_{0}
$$

Uptake at the time $t=0$ was assumed:

$$
(a)_{t=0}=a_{\mathrm{eq}}\left(P_{0}, T_{0}\right)
$$

The temperature of the process water supplied to the first column is equal to the temperature of cooling (adsorption) or heating (desorption) water:

$$
\begin{aligned}
& \left(T_{\mathrm{f}}\right)_{x=0}=T_{\mathrm{f}, \mathrm{ads}} \\
& \left(T_{\mathrm{f}}\right)_{x=0}=T_{\mathrm{f}, \mathrm{des}}
\end{aligned}
$$

The water sub-element has zero heat transfer at the location $x=L$ and at $x=0$ has water temperature from heat distributor $T_{\mathrm{mv}}$ :

$$
\left(T_{\mathrm{f}}\right)_{x=0, t=0}=T_{\mathrm{mv}} \text { and }\left(\frac{\partial T_{\mathrm{f}}}{\partial x}\right)_{x=L}=0
$$

The model assumes perfect insulation, therefore the heat transfer to and from the ambient is equal to zero:

$$
\begin{aligned}
& \left(\frac{\partial T_{\mathrm{t}}}{\partial x}\right)_{x=0}=0 \text { and }\left(\frac{\partial T_{\mathrm{t}}}{\partial x}\right)_{x=L}=0 \\
& \left(\frac{\partial T_{\mathrm{a}}}{\partial x}\right)_{x=0}=0 \text { and }\left(\frac{\partial T_{\mathrm{a}}}{\partial x}\right)_{x=L}=0
\end{aligned}
$$

For adsorption and desorption the pressures were assumed:

$$
\left(P_{\text {ads }}\right)_{t=0}=P_{\text {evap }} \text { and }\left(P_{\text {des }}\right)_{t=0}=P_{\text {cond }}
$$


For each calculation sub-element the heat and mass balance PDE were formulated. The heat balance equation for water sub-element was described:

$$
\frac{\partial T_{\mathrm{f}}}{\partial t}=\frac{\left(-\dot{m} \cdot c_{\mathrm{pf}} \cdot \frac{\partial T_{\mathrm{f}}}{\partial x}+\alpha_{\mathrm{tf}} \cdot\left(2 \cdot \pi \cdot R_{1}\right) \cdot\left(T_{\mathrm{t}}-T_{\mathrm{f}}\right)+\frac{\partial}{\partial x} \cdot\left(\lambda_{\mathrm{f}} \cdot \frac{\partial T_{\mathrm{f}}}{\partial x}\right) \cdot \pi \cdot R_{1}^{2}\right)}{\pi \cdot R_{1}^{2} \cdot \rho_{\mathrm{f}} \cdot c_{\mathrm{pf}}}
$$

The heat balance equation for tube sub-element was described:

$$
\frac{\partial T_{\mathrm{t}}}{\partial t}=\frac{\alpha_{\mathrm{at}} \cdot\left(2 \cdot R_{2}\right) \cdot\left(T_{\mathrm{a}}-T_{\mathrm{t}}\right)-\alpha_{\mathrm{tf}} \cdot\left(2 \cdot R_{1}\right) \cdot\left(T_{\mathrm{t}}-T_{\mathrm{f}}\right)+\lambda_{\mathrm{t}} \cdot\left(R_{2}^{2}-R_{1}^{2}\right) \cdot \frac{\partial^{2} T_{\mathrm{t}}}{\partial x^{2}}}{\left(R_{2}^{2}-R_{1}^{2}\right) \cdot \rho_{\mathrm{t}} \cdot c_{\mathrm{pt}}}
$$

The heat balance equation for adsorbent sub-element:

$$
\frac{\partial T_{\mathrm{a}}}{\partial t}=\frac{\Delta H}{c_{\mathrm{pa}}} \cdot \frac{\partial a}{\partial t}-\frac{\alpha_{\mathrm{at}} \cdot 2 \cdot R_{2}}{\left(R_{3}^{2}-R_{2}^{2}\right) \cdot \rho_{\mathrm{a}} \cdot c_{\mathrm{pa}}} \cdot\left(T_{\mathrm{a}}-T_{\mathrm{t}}\right)+\frac{1}{\rho_{\mathrm{a}} \cdot c_{\mathrm{pa}}} \cdot \frac{\partial}{\partial x} \cdot\left(\lambda_{\mathrm{a}} \cdot \frac{\partial T_{\mathrm{a}}}{\partial x}\right)
$$

The calculation of the complete numerical dynamic model was performed. The mathematical model was solved in POLYMATH 6.0 programming environment.

\section{Validation of the numerical model}

For validation of the numerical model, a comparison with the experimental data of Restuccia et al. [33] has been made. This experimental setup consists of a lab-scale single bed module using a pack of finned stainless steel tubes and the composite sorbent SWS-1L. The geometrical specifications and the operating conditions of the numerical model have been adjusted to their counterparts in the tested lab-scale chilling module with the adsorption/desorption bed. Inlet water heating and cooling temperatures are adjusted to $95{ }^{\circ} \mathrm{C}$ and $40^{\circ} \mathrm{C}$. Other settings such as time control for isobaric and isosteric phases are also considered the same as those in Restuccia [33]. In Figure 7 comparison between the time variations of the numerical and experimental averaged bed temperatures has been made. Reasonable agreement between the results is an indication of the proper mathematical modeling and the accuracy of the numerical scheme.

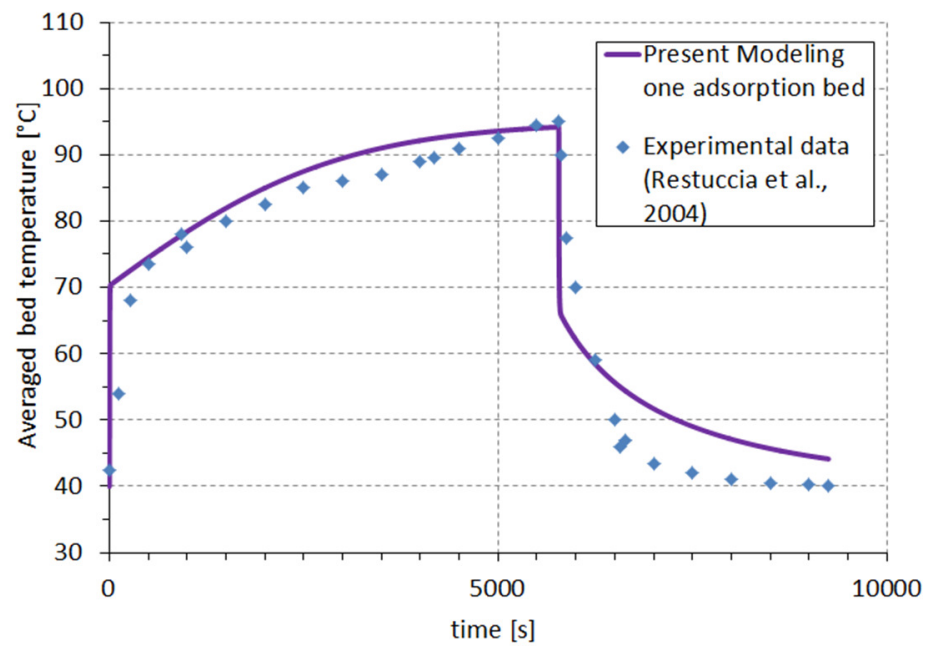

Figure 7. Comparison between the time variations of the numerical (present modeling) and experimental averaged bed temperatures (Restuccia et al. [33]) 


\section{CALCULATION AND RESULTS}

Adsorber/desorber as a part of the two-bed single-stage adsorption heat pump was discussed. The temperature, heat and concentration changes in the adsorber/desorber and consequently the performance of the adsorption heat pump were described. The heating coefficient of performance $\mathrm{COP}_{\text {heating }}$ for the adsorption heat pump has been defined as the ratio of heat extracted during adsorption and in the condenser to the heat supplied by the heating medium (hot water) to the desorber during the regeneration of the silica gel bed:

$$
\mathrm{COP}_{\text {heating }}=\frac{Q_{\mathrm{ads}}+Q_{\text {cond }}}{Q_{\mathrm{des}}}
$$

The cooling coefficient of performance COP cooling for the adsorption heat pump has been defined as the ratio of the heat extracted in the evaporator $Q_{\text {evap }}$ to the heat supplied by the heating medium (hot water) to the desorber during the regeneration of the silica gel bed $Q_{\text {des: }}$ :

$$
\mathrm{COP}_{\text {cooling }}=\frac{Q_{\text {evap }}}{Q_{\text {des }}}
$$

The specific power of the bed (SHP for heating and SCP for cooling) for the adsorption heat pump working cycle was defined as:

$$
\begin{gathered}
\mathrm{SHP}=\frac{Q_{\mathrm{ads}}+Q_{\text {cond }}}{m_{\mathrm{a}} \tau_{\text {cycle }}} \\
\mathrm{SCP}=\frac{Q_{\text {evap }}}{m_{\mathrm{a}} \tau_{\text {cycle }}}
\end{gathered}
$$

where $m_{\mathrm{a}}$ is mass of the adsorbent (only silica gel, without metal). The following parameters of adsorption equilibrium described by the Dubinin-Astakhov model [30] and other parameter values used in the calculation are listed in Table 1.

The 8 calculation cases were chosen to investigate the variables affecting the adsorption/desorption process for the two-bed adsorption heat pump (Table 2). The variables studied were: temperature of desorption which is equal to the hot driving water temperature (range $T_{\mathrm{des}}=353-368 \mathrm{~K}$ ), constant temperature of evaporation $\left(T_{\text {evap }}=288\right)$, temperature of condensation was constant as well and equal $T_{\text {cond }}=313 \mathrm{~K}$. Cycle duration was unchanged in the examined cases $\left(\tau_{\text {cycle }}=\tau_{\text {ads }}+\tau_{\text {des }}=\right.$ $360 \mathrm{~s}$ ). The coefficient of performance was calculated based on eq. (38) and (39) and specific power - based on eq. (40) and (41). The highest $\mathrm{COP}_{\text {heating }}$ was obtained for $4^{\text {th }}$ case $\left(T_{\text {des }}=353 \mathrm{~K}\right)$ and highest temperature difference between $T_{\text {des }}$ and $T_{\text {ads. }}$. The highest $\mathrm{COP}_{\text {cooling }}$ was obtained for $5^{\text {th }}$ case $\left(T_{\text {ads }}=305 \mathrm{~K}\right)$ and highest temperature difference between $T_{\text {des }}$ and $T_{\text {ads }}$ as well. The results of calculations and both described model comparison are shown in Figures 8-14.

The calculated results of adsorber parameters in function of time, for $2^{\text {nd }}$ case described in Table $2\left(T_{\text {cond }}=313 \mathrm{~K}, T_{\text {evap }}=288 \mathrm{~K}, T_{\text {des }}=363 \mathrm{~K}, T_{\text {ads }}=313 \mathrm{~K}, \tau_{\text {cycle }}=360\right.$ s) are presented in Figures 8-10. In Figure 8 calculated cyclic temperature of the adsorbent is shown.

The calculated mean cyclic temperature of the cooling/heating water is presented in Figure 9. The curve from analytical model is characterised by a steep slope at the 
beginning of phase of cycle, and then by almost continuous decreasing with rather small disorder. Possible reason of this is the assumed mechanism of the process pressure change during cycle, mean at the time of isosteric heating and cooling phases (shown in Figure 2). The next reason is the thermal inertia of the adsorber and simplifying assumptions in the mathematical model.

Water vapor (refrigerant) average uptake a on silica gel adsorbent calculated during cyclic operation is shown in Figure 10. In these graphs can be observed the moment of conversion of the adsorber, which is the transition from the adsorption to the desorption process, as a change in direction of the increment values, characterized by a large gradient at the beginning of the curve. This is due, among other things, to a change of pressure and the characteristics of the bed (silica gel) described by Dubinin-Astakhov adsorption isotherms.

In the Figures 11 and 13 the effects of desorption temperature on COP and specific power, respectively, are shown. Calculated $\mathrm{COP}_{\text {heating }}$ and $\mathrm{COP}_{\text {cooling }}$ as a function of adsorption temperature $T_{\text {ads }}$ is presented in Figure 12. In Figure 14 calculated COP in function of specific power is shown.

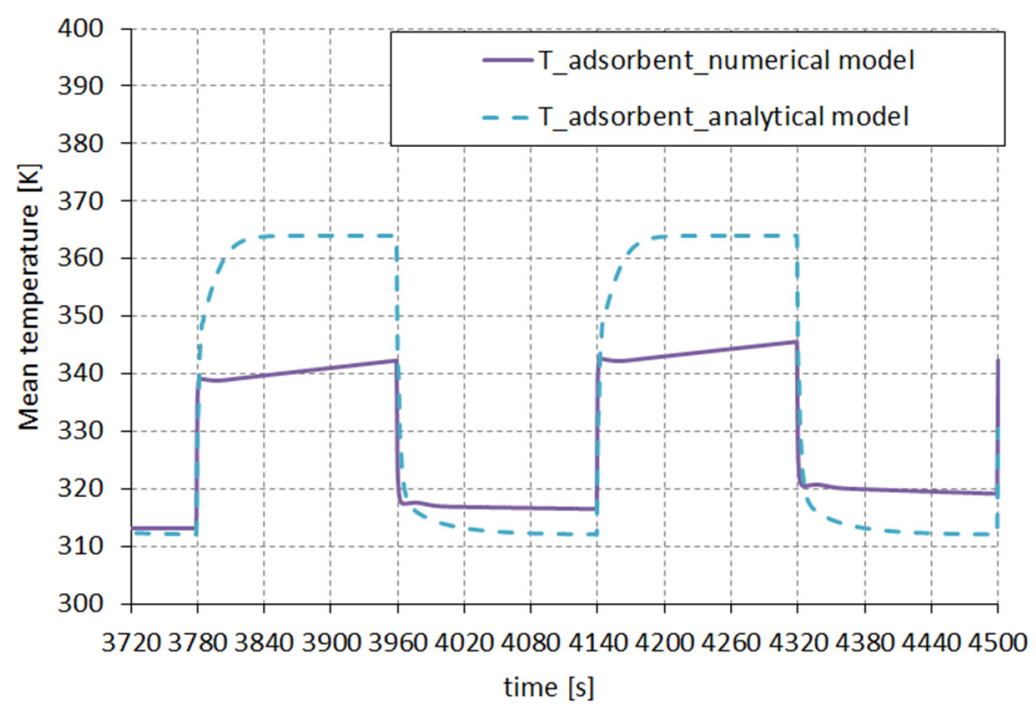

Figure 8. Calculated mean cyclic temperature of the adsorbent at silica gel bed $\left(2^{\text {nd }}\right.$ case, Table 2$)$

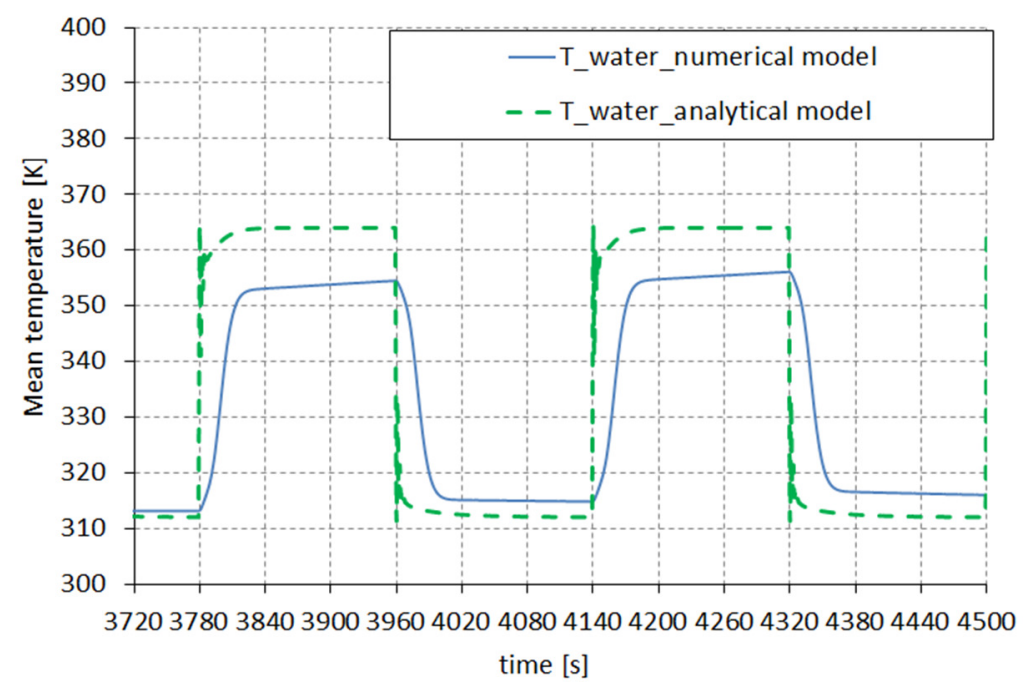

Figure 9. Calculated mean cyclic temperature of the cooling/heating water $\left(2^{\text {nd }}\right.$ case, Table 2$)$ 


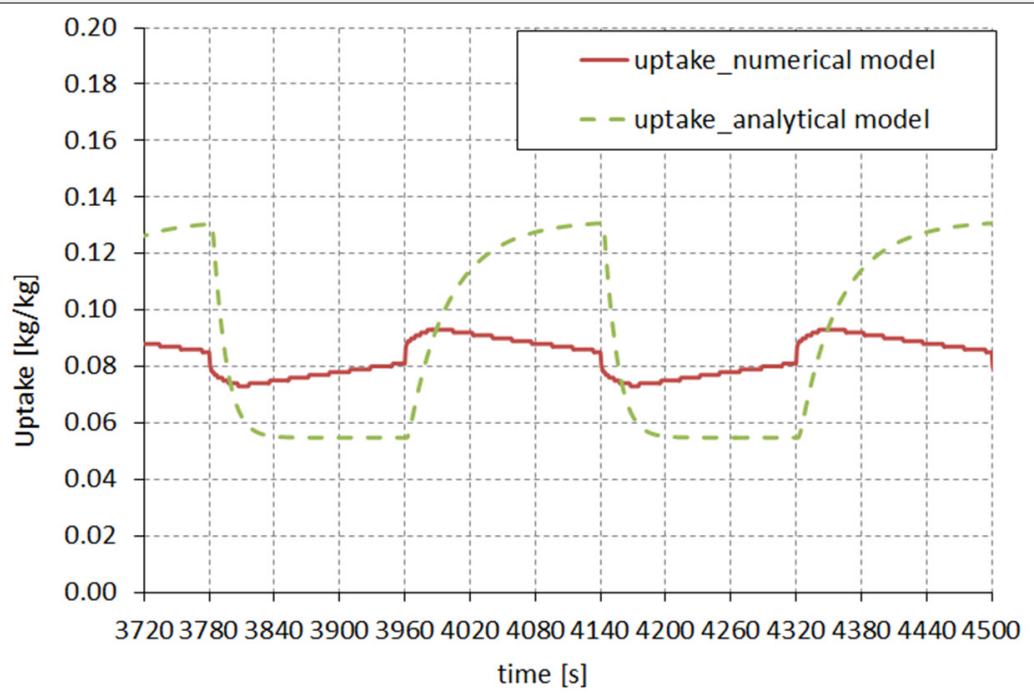

Figure 10. Calculated mean uptake of the water vapor at the silica gel bed $\left(2^{\text {nd }}\right.$ case, Table 2$)$

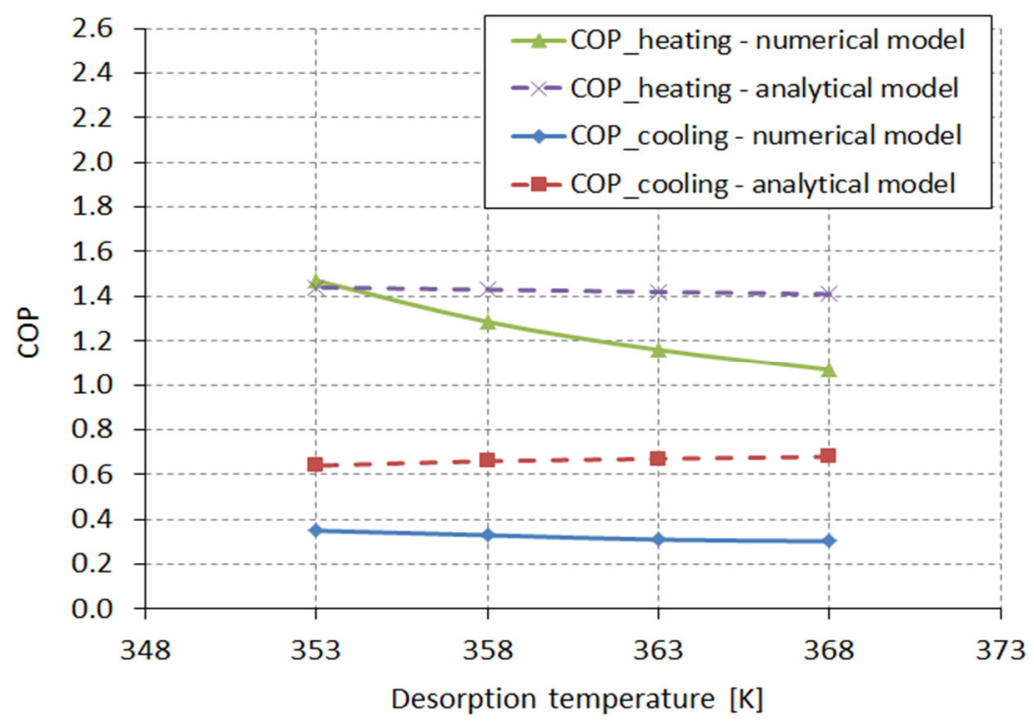

Figure 11. Calculated $\mathrm{COP}_{\text {heating }}$ and $\mathrm{COP}_{\text {cooling }}$ as a function of desorption temperature $T_{\text {des }}$

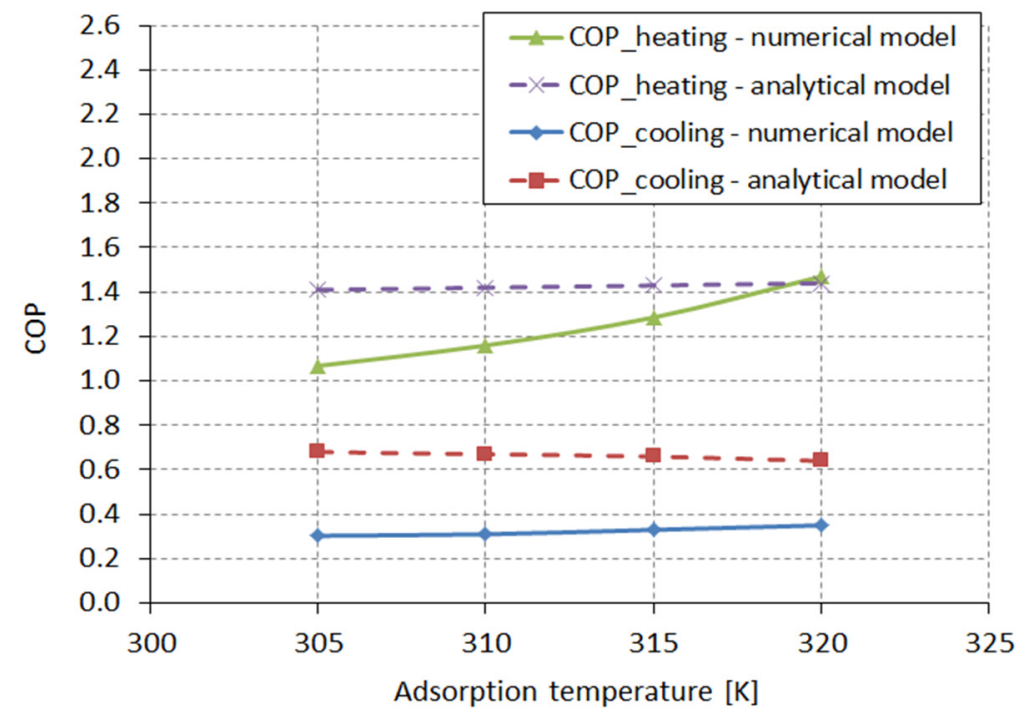

Figure 12. Calculated $\mathrm{COP}_{\text {heating }}$ and $\mathrm{COP}_{\text {cooling }}$ as a function of adsorption temperature $T_{\text {ads }}$ 


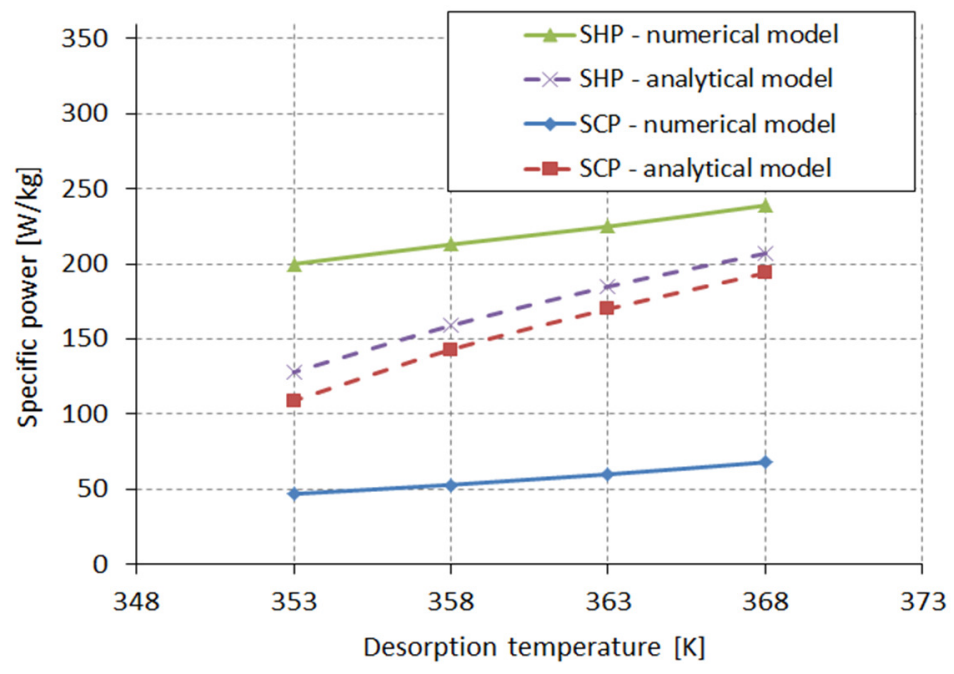

Figure 13. Calculated SHP and SCP as a function of desorption temperature $T_{\text {des }}$

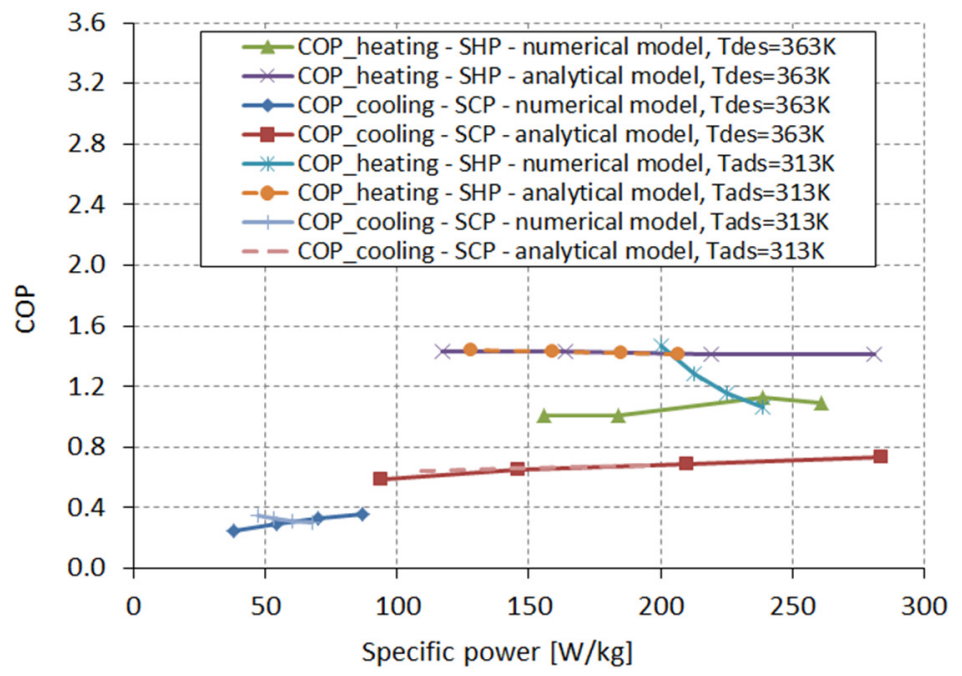

Figure 14. Calculated COP in function of specific power

Table 2. Calculation cases of the adsorption heat pump

$\left(\tau_{\text {cycle }}=360 \mathrm{~s}, p_{\text {ads }}=1.7 \mathrm{kPa}, p_{\text {des }}=7.3 \mathrm{kPa}, \dot{m}_{\text {ads }}=\dot{m}_{\text {des }}=0.01 \mathrm{~kg} / \mathrm{s}, T_{\text {evap }}=288 \mathrm{~K}, T_{\text {cond }}=313 \mathrm{~K}\right)$

\begin{tabular}{|c|c|c|c|c|c|c|c|c|}
\hline \multirow[b]{2}{*}{ No. } & \multirow[b]{2}{*}{$\begin{array}{l}T_{\mathrm{des}} \\
{[\mathrm{K}]}\end{array}$} & \multirow[b]{2}{*}{$\begin{array}{l}T_{\mathrm{ads}} \\
{[\mathrm{K}]}\end{array}$} & \multicolumn{3}{|c|}{$\mathrm{COP}_{\text {heating }}$} & \multicolumn{3}{|c|}{$\mathrm{COP}_{\text {cooling }}$} \\
\hline & & & $\begin{array}{c}\text { Numerical } \\
\text { model }\end{array}$ & $\begin{array}{l}\text { Analytical } \\
\text { model }\end{array}$ & $\begin{array}{l}\text { Absolute \% } \\
\text { difference }\end{array}$ & $\begin{array}{c}\text { Numerical } \\
\text { model }\end{array}$ & $\begin{array}{c}\text { Analytical } \\
\text { model }\end{array}$ & $\begin{array}{c}\text { Absolute \% } \\
\text { difference }\end{array}$ \\
\hline 1 & 368 & 313 & 1.07 & 1.41 & 24.3 & 0.30 & 0.68 & 55.4 \\
\hline 2 & 363 & 313 & 1.16 & 1.42 & 18.3 & 0.31 & 0.67 & 53.7 \\
\hline 3 & 358 & 313 & 1.29 & 1.43 & 10.1 & 0.33 & 0.66 & 50.0 \\
\hline 4 & 353 & 313 & 1.47 & 1.44 & 2.1 & 0.35 & 0.64 & 45.3 \\
\hline 5 & 363 & 305 & 1.09 & 1.41 & 22.7 & 0.36 & 0.73 & 50.7 \\
\hline 6 & 363 & 310 & 1.13 & 1.41 & 19.9 & 0.33 & 0.69 & 52.2 \\
\hline 7 & 363 & 315 & 1.01 & 1.43 & 29.7 & 0.29 & 0.65 & 55.4 \\
\hline 8 & 363 & 320 & 1.01 & 1.43 & 29.5 & 0.25 & 0.59 & 57.6 \\
\hline
\end{tabular}

\section{CONCLUSIONS}

In the paper, comparison of analytical and numerical model of silica gel/water adsorber/desorber was presented. Adsorber/desorber as a part of the two-bed single-stage adsorption heat pump was discussed. 
In the numerical model, for each calculation sub-element (20 sub-elements) of bed (Figure 6), the heat and mass balance PDE were formulated. For validation of the numerical model, a comparison with the published experimental data has been made. Reasonable agreement between the time variations of the numerical and experimental averaged bed temperatures is an indication of the proper mathematical modeling and the accuracy of the numerical analysis.

In the analytical model, the lumped parameters model was assumed for the averaged parameters of the adsorbent and adsorbate. Heat and mass balance equations were written for the whole bed ( 1 element) and temperatures of fluid (water), tube, adsorbent were assumed as averaged in length and in time intervals. Due to many simplifying assumptions adopted, the analytical model developed gives results which differ from the results of the numerical model by about $30 \%$ if we compare the value of $\mathrm{COP}_{\text {heating }}$ or even $50 \%$, if we compare the value of $\mathrm{COP}_{\text {cooling. Developed analytical model is very }}$ basic and can be used only for the initial estimates of mean cyclic temperature of the cooling/heating water in the adsorber/desorber bed.

Analysis of the impact of assessment parameters on operation of adsorber under consideration was performed. The calculation results from the analysis were presented in tables and figures. The 8 calculation cases (Table 2) were chosen to investigate the variables affecting the adsorption/desorption process. The results show the significant role of adsorption/desorption temperatures and adsorption/desorption cycle duration on the performance of the adsorption heat pump. Higher desorption temperature causes decrease in the $\mathrm{COP}_{\text {heating }}$ and small decrease in the $\mathrm{COP}_{\text {cooling }}$ as well. Higher adsorption and desorption temperature difference has an effect on the sorption bed that increase

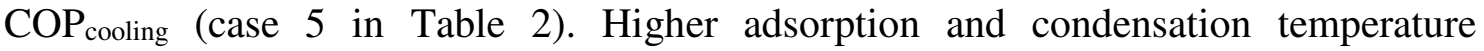

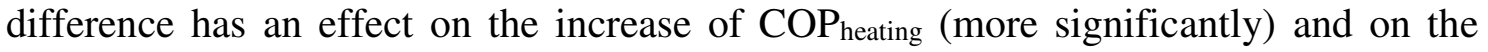
$\mathrm{COP}_{\text {cooling }}$ as well (less significantly). To better investigate pressure and heat parameters further the evaporator/condenser elements need to be expanded in the considered mathematical model.

Further work is connected with comparison between the present analysis and more experiments to reconcile the differences by modifying the analysis and then to develop single-stage multi-bed adsorption systems analysis. It could be advantageous in respect to its power output control and its efficiency optimization.

\section{ACKNOWLEDGEMENT}

This work was supported by the Polish National Science Centre (NCN Poland), grant No. N N512 458440.

\section{NOMENCLATURE}

A adsorption potential

a mass/amount adsorbed/desorbed on adsorbent at time $\tau$

$a_{0}$ adsorption constant, depending on the adsorbent-adsorbate pair specific heat process constant in the mass transport equation

d diameter

$E_{\mathrm{a}} \quad$ activation energy in the mass transport equation

$E_{0} \quad$ characteristic energy of the adsorbent

$H$ heat of vaporization

$\Delta H_{\mathrm{a}} \quad$ isosteric heat of adsorption

$k_{\mathrm{m}} \quad$ constant, specific for the adsorption speed

$k_{\mathrm{l}} \quad$ linear heat transfer coefficient

$\left[\mathrm{J} \mathrm{mol}^{-1}\right]$
$\left[\mathrm{kg} \mathrm{kg}^{-1}\right.$ (uptake) $]$
$\left[\mathrm{kg} \mathrm{kg}^{-1}\right]$
$\left[\mathrm{J} \mathrm{kg}^{-1} \mathrm{~K}^{-1}\right]$
$\left[\mathrm{m}^{2} \mathrm{~s}^{-1}\right]$
$\left[\mathrm{mm}^{-1}\right.$
$\left[\mathrm{J} \mathrm{mol}^{-1}\right]$
$\left[\mathrm{J} \mathrm{mol}^{-1}\right]$
$\left[\mathrm{J} \mathrm{kg}^{-1}\right]$
$\left[\mathrm{J} \mathrm{mol}^{-1}\right]$
$\left[\mathrm{s}^{-1}\right]$
$\left[\mathrm{W} \mathrm{m}^{-1} \mathrm{~K}^{-1}\right]$




$\begin{array}{ll}L & \text { length } \\ m & \text { mass/amount } \\ m_{\mathrm{m}} & \text { mass of } 1 \text { mol of the adsorbate (water vapor) } \\ \dot{m} & \text { mass flow rate } \\ n & \text { constant in the Dubinin-Astakhov equation } \\ p_{\mathrm{s}} & \text { saturation vapor pressure of adsorbate } \\ p & \text { vapor pressure of adsorbate } \\ Q & \text { heat } \\ \dot{Q} & \text { heat flow } \\ R & \text { gas constant } \\ R 1 & \text { tube internal radius } \\ R 2 & \text { tube outer radius } \\ R 3 & \text { adsorbent outer radius } \\ \mathrm{SHP} & \text { specific power } \\ r_{\mathrm{a}} & \text { particle radius } \\ T & \text { temperature } \\ W & \text { heat capacity }\end{array}$

\section{Greek letters}

$\begin{array}{ll}\alpha & \text { heat transfer coefficient } \\ \beta & \text { affinity coefficient } \\ \delta & \text { thickness } \\ \lambda & \text { thermal conductivity } \\ \rho & \text { density } \\ \tau & \text { time }\end{array}$

\section{Superscripts}

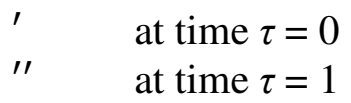

\section{Subscripts}

$\begin{array}{ll}\text { a } & \text { adsorbent } \\ \text { ac } & \text { accumulated } \\ \text { ads } & \text { adsorption } \\ \mathrm{b} & \text { adsorbent + tube } \\ \text { cycle } & \text { cycle } \\ \text { con } & \text { condensation } \\ \text { cond } & \text { condenser } \\ \text { des } & \text { desorption } \\ \text { eq } & \text { equilibrium } \\ \text { ev } & \text { evaporation } \\ \text { evap } & \text { evaporator } \\ \text { ex } & \text { external/outer } \\ \mathrm{f} & \text { fluid (water) } \\ \mathrm{g} & \text { generated } \\ \text { hot } & \text { hot water } \\ \mathrm{i} & \text { elementary time interval } \\ \text { in } & \text { internal/inner } \\ \mathrm{mv} & \text { from heat distributor } \\ \mathrm{t} & \text { tube/pipe } \\ \mathrm{v} & \text { adsorbate (water vapor) }\end{array}$




\begin{tabular}{ll}
\hline $\mathrm{r}$ & removed \\
$\mathrm{s}$ & supplied \\
$\mathrm{LE}$ & left \\
$\mathrm{RI}$ & right
\end{tabular}

\section{Abbreviations}

COP Coefficient Of Performance

\section{REFERENCES}

1. Wongsuwan, W., Kumar, S., Neveu, P. and Meunier, F., A Review of Chemical Heat Pump Technology and Applications, Appl. Therm. Eng., Vol. 21, No. 15, pp 1489-1519, 2001, http://dx.doi.org/10.1016/S1359-4311(01)00022-9

2. Restuccia, G. and Cacciola, G., Performances of Adsorption Systems for Ambient Heating and Air Conditioning, Int. J. Refrig., Vol. 22, No. 1, pp 18-26, 1999, http://dx.doi.org/10.1016/S0140-7007(97)00078-9

3. Chahbani, M. H., Labidi, J. and Paris, J., Modeling of Adsorption Heat Pumps with Heat Regeneration, Appl. Therm. Eng., Vol. 24, No. 2-3, pp 431-447, 2004, http://dx.doi.org/10.1016/j.applthermaleng.2003.08.012

4. Wang, R. Z., Wu, J. Y., Xu, Y. X. and Wang, W., Performance Researches and Improvements on Heat Regenerative Adsorption Refrigerator and Heat Pump, Energy Conver. Manag., Vol. 42, No. 2, pp 233-249, 2001, http://dx.doi.org/10.1016/S0196-8904(99)00189-2

5. San, J-Y. and Hsu, H-Ch., Performance of a Multi-bed Adsorption Heat Pump using SWS-1L Composite Adsorbent and Water as the Working Pair, Appl. Therm. Eng., Vol. 29, No. 8-9, pp 2009, http://dx.doi.org/10.1016/j.applthermaleng.2008.07.008

6. Anyanwu, E. E., Review of Solid Adsorption Solar Refrigeration II: An Overview of the Principles and Theory, Energy Conver. Manag., Vol. 45, No. 7-8, pp 1279-1295, 2004, http://dx.doi.org/10.1016/j.enconman.2003.08.003

7. Wang, L. W., Wang, R. Z., Wu, J. Y., Xia, Z. Z. and Wang, K., A New Type Adsorber for Adsorption Ice Maker on Fishing Boats, Energy Conver. Manag., Vol. 46, No. 13-14, pp 2301-2316, 2005, http://dx.doi.org/10.1016/j.enconman.2004.09.010

8. Hamdan, M. A., Rossides, S. D. and Haj Khalil, R., Thermal Energy Storage using Thermo-chemical Heat Pump, Energy Conver. Manag., Vol. 65, pp 721-724, 2013, http://dx.doi.org/10.1016/j.enconman.2012.01.047

9. Tien, C., Adsorption Calculation and Modeling, Butterworth-Heinemann, Boston, USA, 1994.

10.Bathen, D. and Breitbach, D., Adsorptionstechnik, Springer, Berlin, Germany, 2001.

11.Rousseau, R. W., Handbook of Separation Process Technology, John Wiley \& Sons, USA, 1987.

12.Ambrozek, B. and Zwarycz-Makles, K., Theoretical and Experimental Studies of the Recovery of Volatile Organic Compounds from Waste Air Streams in the Thermal Swing Adsorption System with Closed-loop Regeneration of Adsorbent, Energy Conver. Manag., Vol. 85, pp 646-654, 2014, http://dx.doi.org/10.1016/j.enconman.2014.03.055

13.Demira, H., Mobedi, M. and Ülkü, S., A Review on Adsorption Heat Pump: Problems and Solutions, Renew. Sust. Ener. Rev., Vol. 12, No. 9, pp 2381-2403, 2008, http://dx.doi.org/10.1016/j.rser.2007.06.005

14.Meunier, F., Solid Sorption Heat Powered Cycles for Cooling and Heat Pumping Applications, Appl. Therm. Eng., Vol. 18, No. 9-10, pp 715-729, 1998, http://dx.doi.org/10.1016/S1359-4311(97)00122-1 
15.Wu, J. Y., Wang, R, Z. and Xu, Y. Z., Dynamic Simulation and Experiments of a Heat Regenerative Adsorption Heat Pump, Energy Conver. Manag., Vol. 41, No. 10, pp 1007-1018, 2000, http://dx.doi.org/10.1016/S0196-8904(99)00161-2

16.Gong, L. X., Wang, R. Z., Xia, Z. Z. and Chen, C. J., Design and Performance Prediction of a New Generation Adsorption Chiller using Composite Adsorbent, Energy Conver. Manag., Vol. 52, No. 6, pp 2345-2350, 2011, http://dx.doi.org/10.1016/j.enconman.2010.12.036

17.Pilatowsky, I., Romero, R. J., Isaza, C. A., Gamboa, S. A., Sebastian, P. J. and Rivera, W., Cogeneration Fuel Cell-sorption Air Conditioning Systems, Springer, London, UK, 2011.

18.Wang, D., Zhang, J., Xia, Y., Han, Y. and Wang, S., Investigation of Adsorption Performance Deterioration in Silica Gel-water Adsorption Refrigeration, Energy Conver. Manag., Vol. 58, pp 157-162, 2012, http://dx.doi.org/10.1016/j.enconman.2012.01.013

19.Gwadera, M. and Kupiec, K., Adsorption Cooling Systems (in Polish), Inż. Ap. Chem., Vol. 5, pp 38-39, 2011.

20.Ambrozek, B., Zwarycz-Makles, K. and Szaflik, W., Equilibrium and Heat of Adsorption for Selected Adsorbent-adsorbate Pairs used in Adsorption Heat Pumps, Polska Energetyka Stoneczna (Polish Solar Energy), Vol. 1-4, pp 5-11, 2012.

21.Rege, S. U., Yang, R. T. and Buzanowski, M. A., Sorbents for Air Prepurification in Air Separation, Chem. Eng. Sci., Vol. 55, No. 21, pp 4827-4838, 2000, http://dx.doi.org/10.1016/S0009-2509(00)00122-6

22.Wang, Y. and LeVan, M. D., Adsorption Equilibrium of Carbon Dioxide and Water Vapor on Zeolites 5A and 13X and Silica Gel Pure Components, J. Chem. Eng. Data.,Vol. 54, No. 10, pp 2839-2844, 2009, http://dx.doi.org/10.1021/je800900a

23.Lee, J. S., Kim, J. H., Kim, J. T., Suh, J. K., Lee, J. M. and Lee, C. H., Adsorption Equilibria of $\mathrm{CO}_{2}$ on Zeolite $13 \mathrm{X}$ and Zeolite X/Activated Carbon Composite, J. Chem. Eng. Data., Vol. 47, No. 5, pp 1237-1242, 2002, http://dx.doi.org/10.1021/je020050e

24.Akisawa, A. and Miyazaki, T., Multi-bed Adsorption Heat Pump Cycles and their Optimal Operation, Advances in Adsorption Technology (Saha, B. B. and Ng, K. C., eds.), Nova Science Publishers Inc., pp 241-279, 2010.

25.Zwarycz-Makles, K., Kuczynski, K. and Ambrozek, B., Modeling of Adsorption Heat Pump Integrated with District Heating Network (Xu, J., Jin, H., Lior, N. and Zhang, N., eds.), ECOS 2013: Proceedings of the $26^{\text {th }}$ International Conference on Efficiency, Cost, Optimization, Simulation and Environmental Impact of Energy Systems, July 16-19, Guilin, China, B013, 2013.

26.Zwarycz-Makles, K. and Szaflik, W., Mathematical Model of Adsorber of the Adsorption Heat Pump with Variable Adsorber Temperature (Ban, M., Duic, N., Guzovic, Z., Markovska N., et al., eds.), SDEWES 2013: Proceedings of the $8^{\text {th }}$ Conference on Sustainable Development of Energy, Water and Environment Systems, Sep. 22-27, Dubrovnik, Croatia, Faculty of Mechanical Engineering and Naval Architecture, Zagreb, 0812-1, 2013.

27.Zwarycz-Makles, K., Szaflik, W. and Kuczynski, K., Comparative Analysis of Mathematical Models of a Silica Gel-water Adsorber of the Adsorption Heat Pump, ECOS 2014: Proceedings of the 27th International Conference on Efficiency, Cost, Optimization, Simulation and Environmental Impact of Energy Systems, June 15-19, Turku, Finland, 340-1, 2014.

28.Park, I. and Knaebel, K. S., Adsorption breakthrough Behavior: Unusual Effects and Possible Causes, AIChE Journal, Vol. 38, No. 5, pp 660-670, 1992, http://dx.doi.org/10.1002/aic.690380504

29.Coulson, J. M. and Richardson, J. F., Chemical Engineering Design, Vol. 6, $4^{\text {th }}$ ed., Sinnot, R. K., 2005. 
30.Do, D. D., Adsorption Analysis: Equilibria and Kinetics, Imperial College Press, London, 2008.

31.Leong, K. C. and Liu, Y., Numerical Modeling of Combined Heat and Mass Transfer in the Adsorbent Bed of a Zeolite/water Cooling System, Appl. Therm. Eng., Vol. 24, No. 16, pp 2359-2374, 2004, http://dx.doi.org/10.1016/j.applthermaleng.2004.02.014

32.Zwarycz-Makles, K. and Kuczynski, K., Model of Six-bed Silica Gel-water Adsorption Heat Pump used for Heating, Proceedings of the $17^{\text {th }}$ Conference on Process Integration, Modelling and Optimisation for Energy Saving and Pollution Reduction (Pres 2014), 23-27 August, Prague, Czech Republic, 1077, 2014.

33.Restuccia, G., Freni, A., et al., Selective Water Sorbent for Solid Sorption Chiller: Experimental Results and Modeling, Int. J. Refrig., Vol. 27, pp 284-293, 2004, http://dx.doi.org/10.1016/j.ijrefrig.2003.09.003 